\title{
Humanização como processo conflitivo, coletivo e contextual
}

\author{
Humanization as a conflictive, collective and contextual process \\ Humanización como proceso conflictivo, colectivo y contextual
}

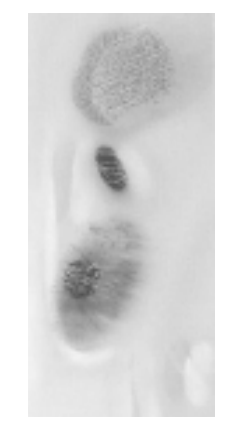

Denise Gastaldo ${ }^{1}$

Este comentário apresenta as reflexões que a leitura do texto de Regina Benevides e Eduardo Passos me suscitaram. Escrevo uma quase-resposta, acrescentando algumas novas idéias a questões que para mim ficaram pendentes, numa tentativa de diálogo. Após descrever como leio o texto dos autores, passarei às três questões que considero importantes discutir: 1. a relatividade e diversidade na humanização como problemáticas; 2. a tensão entre o individual e o coletivo no processo de mudança social; e 3. a produção de humanização como prática numa sociedade fortemente desumanizada.

Benevides e Passos mostram-se críticos da rigidez de conceitos, como o conceitosintoma de humanização porque "paralisa e reproduz um sentido já dado" e está fragmentado na prática por programas, níveis de atenção e profissões, entre outros. Esta forma de pensar conduz a uma crítica da normalização, pois não captura a singularidade de nenhum indivíduo em particular, e da tendência de se idealizar aspectos de nossa humanidade, enquanto o que é criativo, reciclado ou marginal freqüentemente é rechaçado pelo sistema. Ao apostar na diversidade normativa e numa reflexão que contemple vários coletivos, os autores crêem que as pessoas se transformariam ao participar de estratégias de mudança social. No que tange à humanização como política pública, sugerem que é necessário superar abstrações para que a política chegue aos atores sociais e estes experimentem formas de se relacionar em co-gestão com o sistema, no qual a produção de saúde seja também produtora de subjetividades.

${ }^{1}$ Associate Professor; Faculty of Nursing \& Department of Public Health Sciences; Faculty of Medicine; University of Toronto, Canada. <denise.gastaldo@utoronto.ca> 
Minha primeira reação ao texto foi pensar que o pedido de diversidade e valorização da diferença não combinava com o vocábulo "Homem" para descrever os seres humanos de ambos os sexos e distintas orientações sexuais.

Pessoalmente, não percebo a humanidade em sua diversidade na palavra homem, seja ela com maiúscula ou minúscula. A seguir, numa reflexão um pouco mais detida, percebi que minha reação ao texto era de incredulidade nas propostas de humanização ali levantadas por sua relatividade, pela ausência de uma descrição explícita dos valores e tipos de subjetividades desejados pela política de humanização, um problema freqüente em textos de orientação pós-estruturalista e pósmoderna. Reconheço que os autores apontam para a co-gestão, trocas solidárias e comprometidas, mas estes são valores de processo mais do que efeitos desejados. Ou seja, é preciso humanizar porque o sistema é considerado hoje, por alguns - entre eles os formuladores da política - como desumano, inadequado, ineficiente etc. Neste contexto, não estamos falando de produção de subjetividades em geral, mas de alguns tipos de subjetividade e, assim, o processo de humanizar-se não é menos prescritivo que qualquer outro, mesmo quando explicita a diversidade como valor que deve orientar o processo de humanizar-se.

A criação de subjetividades ocorre hoje nas práticas do cotidiano do SUS e este processo, de subjetividades criadas e re-criadas, gera grande parte da resistência ao que se propõe como humanização. Infelizmente, receio que se fizéssemos prevalecer o pensamento dos(as) profissionais que trabalham para o SUS hoje, além de uma óbvia diversidade de opiniões, talvez nos deparássemos com muitos que pensam que sistema público é "assim mesmo", que com as atuais condições de trabalho e os limites educacionais e financeiros da população "a gente faz o que pode". Esta é uma subjetividade, a de vítima do sistema ou da situação. Outra é a subjetivação de privilégios, na qual alguns médicos(as) se percebem menos responsáveis por cumprir horário que outros profissionais, pois eles "precisam" ter um melhor salário. Ou seja, o SUS, desde sua criação, colabora na produção de formas de pensar e praticar cuidados e tratamentos de doenças e, neste processo, se produzem subjetividades individuais que têm muitas características compartilhadas no coletivo.

Uma outra lacuna no texto, também derivada de seu relativismo, é a ausência de referências a conflitos e sistemas de privilégios. Suponho que o atendimento desumanizado seja benéfico para alguns, pois se a desumanidade na atenção fosse ruim para todas as pessoas envolvidas já teríamos presenciado mudanças mais abrangentes. Além disso, o discurso da valorização da diferença tem, à primeira vista, um caráter imobilizador, se não for mediado por valores explícitos. Como se deve respeitar todas as diferenças (inclusive as que desumanizam o sistema) e estas apontam para caminhos distintos na implementação de programas e práticas, na micro-física das relações de poder do cotidiano torna-se difícil justificar uma forma de atuação sobre outra, por exemplo: valorizar o horário que é mais conveniente à população que aos trabalhadores.

Esta crítica não se deve ao fato de que eu ignore os objetivos e valores claramente definidos para o SUS, os quais servem de marco para o desenvolvimetno da política de humanização. Também entendo que, no cotidiano dos serviços, a tradução de princípios como universalidade ou integralidade necessitam do que os autores descreveram como políticas transversais que ajudem a concretização de práticas humanizadas. No entanto, humanizar é explicitar agendas e conflitos. Por exemplo, na gestão de diferenças de gênero, como trabalhar o acolhimento e o suporte emocional se não nos referimos ao papel social que está atrelado às mulheres nesta área porque vivemos numa sociedade com marcados valores patriarcais? Ou, como responder a questões de desigualdade de 
gênero vivenciadas pelas clientes se estas também permeiam as relações de trabalho, talvez de formas mais sutis?

Os exemplos que utilizei até o momento remetem a meu segundo ponto. Um dos possíveis resultados de um processo coletivo de busca de humanização nos serviços pode ser uma ruptura nas relações da equipe, pois subjetividades antagônicas se consolidam no grupo. Talvez isso seja parte do processo que os autores descrevem como construção coletiva, mas tenho dificuldade de entender a sintonia do processo de indivíduos e coletivos que eles relatam. Parto da premissa que discursos dominantes e emergentes constituem as subjetividades de pessoas que participam de um mesmo processo e que elas transformam suas subjetividaes de maneiras díspares no processo de tentar atingir um mesmo objetivo. Assim, uma vez mais, acredito que a noção de conflito ou co-existência de rupturas e continuidades que co-existem na produção de subjetividades pode ser útil para entender o processo de busca de práticas e visões de mundo mais próximas a um sistema de saúde humanizado para usuários(as) e profissionais.

A última questão que me ocorre a partir da leitura do texto é a de que a política de humanização tem diante de si um desafio incomensurável: o de humanizar numa sociedade em que prevalecem tantas e tão profundas formas de injustiça e violência no cotidiano, a desumanidade à brasileira. O colonialismo, transformado no último século em um acentuado classismo, e as persistentes expectativas de subserviência da população economicamente desfavorecida, ou negra, ou feminina, por parte de muitos em nossa sociedade permeiam as relações do cotidiano a ponto de ser muito difícil distingüir exterioridade e interioridade neste processo. Considero também importante lembrar que o acesso a serviços de saúde de qualidade é apenas um entre mais de uma dezena de determinantes sociais da saúde, como distribuição eqüitativa de renda, inclusão social, condições de trabalho e educação... Além disso, os serviços de saúde são responsáveis por apenas 10 a $15 \%$ de todos os cuidados de saúde que ocorrem nas sociedades de países ditos desenvolvidos, estando a cargo da sociedade a maior parte dos cuidados.

Para concluir, quero ressaltar que em muitos pontos concordo com os autores, mas como acadêmica cabe a mim fazer críticas para aprimorar formas de teorizar e praticar a promoção da saúde. Em síntese, sugiro que a teoria desenvolvida por Benevides e Passos se beneficiaria de maior atenção aos conflitos e tensões que o processo de humanização poderá desencadear, inclusive nos processos de produção de subjetividades, de uma pauta de diversidade para assegurar a inclusão social, o que é benéfico para a saúde de toda população e, finalmente, de uma reflexão do significado da proposta de humanização do SUS no contexto da desumanidade dos determinantes sociais da saúde, aos quais a maioria da população brasileira está submetida em seu cotidiano.

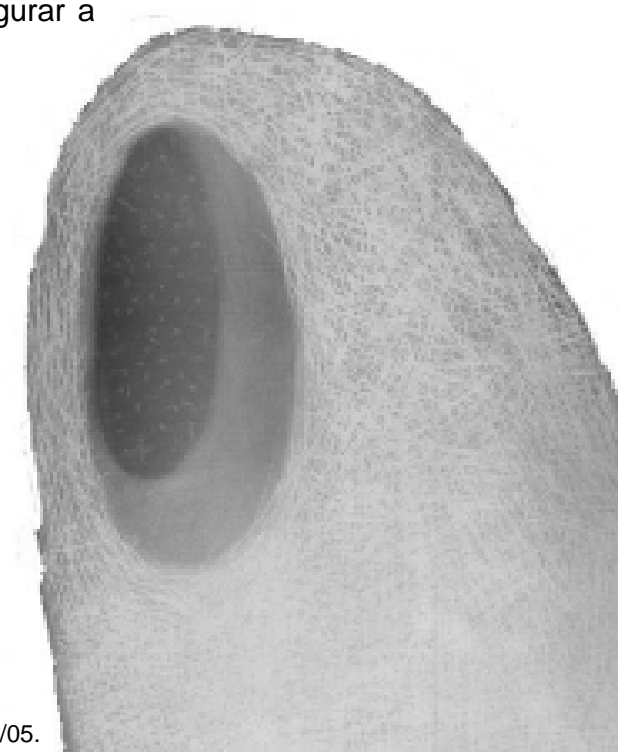

